\title{
The Development of the Authorized Valve Distributors POS Data Management System
}

\author{
Princess Ann Muyo \\ University of the East Manila, \\ Philippines
}

\author{
August Anthony N. Balute \\ University of the East Manila, \\ Philippines
}

\author{
Dennis B. Gonzales \\ University of the East Manila, \\ Philippines
}

\begin{abstract}
In the modern world of business, data is considered to be one of the most valuable assets of an organization. It is the "raw material" of every vital and strategic action taken by top executives and managers in running the business. Data defines each association's uniqueness and should be carefully cultivated, managed, and refined into information which will allow them to better serve their organization and ensure its viability in today's competitive landscape.

Timely and accurate data is vital to achieve effective business intelligence. High-tech companies are allotting huge annual budget to collect, clean and analyze their channel data in order to gain visibility into their channel business, market share and pricing pressure, and create the right sales incentives for their internal and channel sales organizations.

The proponent will propose in this study an integrated system to properly manage [1] ASCO Authorized Valve Distributors Point-Of-Sale data. In this chapter, the proponent will discuss the background of the study, its objectives, significance, and scopes and limitations that will serve as a guide for readers to better understand the whole concept.
\end{abstract}

\section{Keywords}

Web Services, Data Normalization, Flat File Transfer, Service Level Agreement, Unrestricted Scalability

\section{INTRODUCTION}

[2] ASCO is an Emerson business unit headquartered in 160 Park Avenue, Florham Park, New Jersey, 07932. In 1910, the company invented the solenoid valve - an electromechanically operated valve which is controlled by an electric current through a cylindrical coil of wire acting as a magnet.

At present, ASCO offers comprehensive solutions of fluid automation products for a broad range of process and manufacturing industry applications. The company's fluid control and pneumatic product lines include a full range of solenoid valves, angle body piston valves, valve manifolds, cylinders, filters, regulators, lubricators and a complete range of accessories.

ASCO in the Philippines is a shared service supporting ASCO US, ASCO Europe and ASCO Asia. Among the services the local unit provides are Engineering, Customer Service, Technical Support, and Marketing.

The proponent is managing the ASCO US Reporting Services Group under Marketing umbrella. Nevertheless, the team generally supports both marketing and sales team in the whole Americas. At present, the proponent handles six (6) Reports Analysts and one (1) Analyst-Programmer. The group's core responsibilities are, but not limited to, the following:

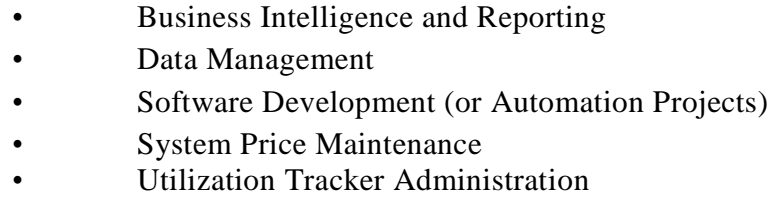

Data Management. In this particular role, the team is managing the point-of-sale (POS) data of US Authorized Valve Distributor (AVD). AVDs are customers who are regularly submitting POS data to ASCO on a monthly basis, as part of the company's requirement in distributor accreditation.

\section{Importance of AVD POS Data to ASCO US}

ASCO US domestic customers are categorized into five (5) types:

- Original Equipment Manufacturer

- Distributor

- $\quad$ Authorized Valve Distributor - Original Equipment Manufacturer

- Assembler

- Direct User

Original Equipment Manufacturer (OEM) is a company that makes a part or subsystem that is used in another company's end product. This entity usually requests and orders customized ASCO products based on their specific need. Hence, most of these items are proprietary to them.

Distributor is a type of customer that purchases products of ASCO for reselling to retailers or directly to product end users. ASCO has different types of distributors Authorized Valve Distributors, Authorized Pneumatic Distributors, and Niche Distributors.

Authorized Valve Distributor - Original Equipment Manufacturer (AVD-OEM) is the only distributor authorized to sell to OEMs. Take note that not all ASCO distributors are permitted to sell to OEM since most items purchased by the manufacturer are proprietary.

Assembler is an entity that uses ASCO item as one of the part item to produce a new product. Unlike OEM, assembler does not purchase customized items.

Direct User is the customer which uses ASCO item for personal, commercial or other purposes.

Shown in Figure 1.4 is the percentage contribution of the overall ASCO US Domestic Sales per customer type from 2011 to 2015 . Based on the graph, distribution is the largest contributor covering more than half of the overall ASCO US domestic sales. 


\section{REVIEW OF RELATED LITERATURES}

(Malcolm Tatum, 2010) Tatum defined point of sale as the exact point in a transaction when goods or services are provided to the customer and payment is rendered for those products.

[3] (DAMA-DMBOK, 2014). [4] DAMA International, an organization for data management professionals, defined data management as "the development, execution and supervision of plans, policies, programs and practices that control, protect, deliver and enhance the value of data and information assets".

At present, technology plays a vital role in effective and efficient data management. According the Business Dictionary website, data management technology involves skills and equipment used to organize, secure, store and retrieve information. It can be referred to a wide range of techniques and database systems used for managing information use and allocating access both within a business and between entities.

[5] (Paul Christ, 2012). In the second edition of "Know This: Marketing Basics", Christ discussed the significance of distribution to the business. He stated that distribution channels often require the assistance of others in order for the marketer to reach its target market. It may appear that operating own distribution channel is a more sensible manner to take for companies, however, there are several factors preventing the management to do so. Companies can stand alone without the assistance of certain channel members. Nevertheless, some level of channel partnership is vital for many marketers.

A marketer must know the value a channel member can offer to the firm in choosing a distribution strategy. Therefore, selecting a channel partner involves a value analysis which must be supported by a cost-and-benefit study.

Christ had enumerated the benefits a firm can get from their channel members. Those are:

$\begin{array}{ll}\text { - } & \text { Cost Savings in Specialization } \\ \text { - } & \text { Reduce Exchange Time } \\ \text { - } & \text { Resellers sell smaller quantities } \\ \text { - } & \text { Create sales } \\ \text { - } & \text { Offer financial support } \\ & \text { Provide information }\end{array}$

One of the advantages the companies can get from their channels are the information they get from distributors which can help improve the product. High-level intermediaries may offer their suppliers real-time access to sales data including information showing how products are selling. The material usually includes geographic location, customer type, and product location. If the channel has no capability or does not permit to present such information, marketers can often count on resellers to provide feedback as to how customers are responding to products. This information is usually gathered through surveys or interviews with reseller's employees and customers, if allowed by the channel partner.

[6] (Quinn E., 2013). In the article written by Dimbrero under the B2B Marketing section in Chief Marketer website, he defined channel data management $(\mathrm{CDM})$ as a fast-growing discipline among large manufacturers that increases company visibility into finer details within their sales and distribution channels activities. He added that CDM is designed to deliver decision-grade channel intelligence leading to increased sales and improved incentive program return-of-investment (ROI).

Moreover, Dimbrero stated that with automated CDM, manufacturers can boost their channel sales by responding to their channels precise data, produce better-targeted promotions, and engineer a more effective partner segmentation. They can also influence an in depth understanding of customers to enhance regional sales performance and new product planning.

[7] According to the 2013 report of Forrester Research, entitled "Market Overview: Channel Data Management", CDM solutions obtain POS and inventory data from businessto-business (B2B) organizations' partners and convert it into high-quality insights to lift channel processes and plans. Data gathered from partners is cleansed, standardized, and integrated into the organization's existing Customer Relationship Management (CRM) / Partner Relationship Management (PRM) / Enterprise Resource Planning (ERP) system to provide channel management with visibility into every partner and end user transaction.

[8] (Chanan Greenberg, 2015). Greenberg believes that channel data is important to the companies as it provides visibility into the sales activities in their channels, into inventory levels, market penetration in geographies and new application markets. Nevertheless, gathering these information is not as easy as everyone thinks. Greenberg listed and discussed the challenges accompanied with this discipline.

- Timeliness - Due to variety of data sources and systems used by the channels, Greenberg mentioned that multiple companies are challenged with different cadence of POS and Inventory reports, late and incorrect submissions, EDI error issues, and worst comes to worst, no submission at all. He stated that companies missed to collect as much as twenty-five percent $(25 \%)$ of the overall channel data. In order to solve these issues, Greenberg believes that the management should have the willingness to spend time, energy, and manpower to handle this process.

- Cleanliness - According to Greenberg, channel data is "notoriously" dirty. Some examples of unclean data are misspelled customer names, errors in product SKU numbers, prices, and dates. Most of the time, information provided is incomplete. Companies allot a big chunk of their budget to develop smart tools, fuzzy logic, algorithms, and people's time to bring the raw data into a more useful information and dataset.

- Data to Information and Insight - After gathering and cleaning the raw data from the channel, all efforts will be useless unless it is converted into information and insight. Greenberg said that the data must be enriched with missing information, segmented, and categorized based on markets, geographies, applications, channels, customer types, and more. These classifications can be used as a source of business intelligence (BI) which management uses in data-driven decision making.

- Insight to Action - When using POS and inventory data to drive daily business transactions, channel data must be relied upon. Most companies currently depend on a set of manual processes and homegrown integrations to manage such processes. 


\subsection{Related Studies}

Upon research, there are only few software companies which provide CDM solutions. One of which is Zyme. Based on their website, Zyme is the global leader in the emerging CDM space, empowering the New Smart Channel' ${ }^{\mathrm{TM}}$, a proven approach in creating visibility to actionable insight that manufacturers need to boost up partner sales and optimize marketing program ROI.

zymeCDM $^{\text {SM }}$ is Zyme's flagship CDM solution. It offers end-to-end CDM capabilities that turn raw channel data into actionable channel intelligence. The tool's framework is shown in Figure 2.1 below:

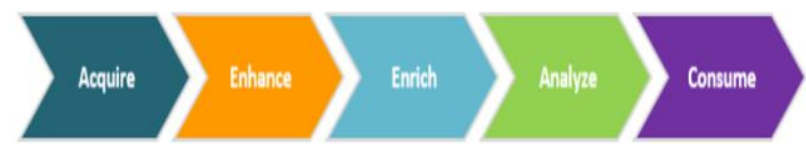

Figure 1. zyme CDM

Zyme automatically collects data submission from partners in any format and mode through $\mathrm{zymeCDM}^{\mathrm{SM}}$. To ensure an automated, real-time, error-free data submission, the software is empowered by an integration gateway called Zyme Feed.

After gathering the data, zymeCDM ${ }^{\mathrm{SM}}$ certifies the quality of acquired information through powerful normalization and validation to ensure its integrity.

The third process would be further supplementing the high quality data with customer-specific enrichments through lookup against customer master catalogs, and reference data.

The normalized, validated and enriched data is then sent to customers as feed out to be integrated with their downstream systems. Data can also be fed into Zyme's analytics tools or dashboards so that customers can analyze the data and make critical business decisions in a snap.

Clean, enhanced and enriched data from zymeCDM ${ }^{\mathrm{SM}}$ can be seamlessly integrated into customer's downstream CRM, ERP and data warehouses for easy consumption.

With complete visibility into the distribution channel data and actionable intelligence, zymeCDM ${ }^{\mathrm{SM}}$ offers the following advantages to customers.

- Improve channel revenue by more than $5 \%$

- Optimize sales force utilization

- Optimize channel marketing spend

- Reduce inventory and logistics costs

- Reduce channel audit effort and cost

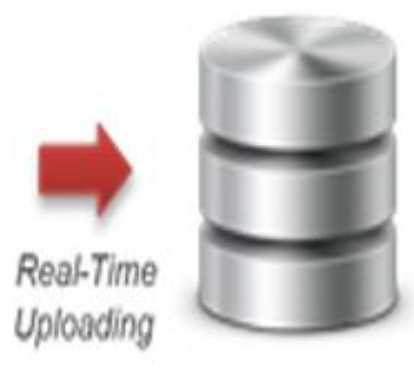

Local Database

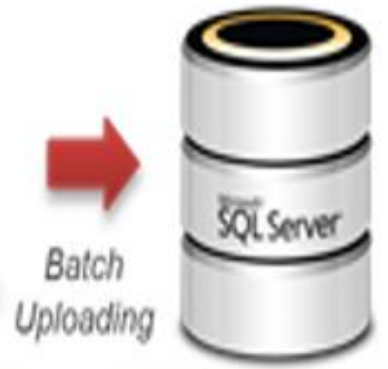

Central Server
Figure 2. Conceptual Framework
In the previous chapter, it was discussed and presented that more than half of the ASCO US domestic sales are coming from channels, particularly distribution. Thus, it is important for the company to gather the end customers' data to have a bigger scope in monitoring sales activities. To begin with the study, the proponent researches for related literatures and studies which will help in planning, assembling and implementing this capstone project.

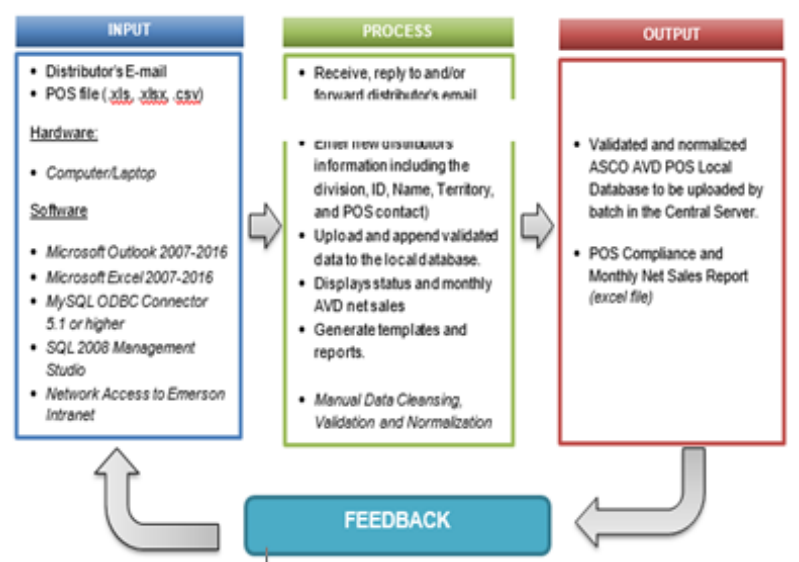

Figure 3. Theoretical Framework

Dimbero defined CDM as a discipline that enhances the companies' visibility into the fine details of what is happening within their sales and distribution channels. The proponent was able to gather useful insights from Arora and Greenberg about the features to look for in an effective channel data management system. Moreover, Greenberg also discussed the challenges in channel data gathering and processing, which was also tackled in the study of Thurmond.

The theoretical and conceptual framework formed by the proponent was also engineered with zymeCDMSM framework. The experience of DLink, a client of Zyme, in managing channel sales data is somewhat similar to ASCO. This served as guide for the proponent in planning the software development of ASCO AVD POS Data Management System.

\section{METHODOLOGY \\ 3.1 Research Design}

This research is guided through purposive sampling method. The proponent believes that the said research design is the best technique to take since the system will only be utilized by specific people from the organization. These selected respondents are knowledgeable in the existing process of ASCO in managing AVD POS data.

In the e-book entitled "The Ultimate Guide to Writing a Dissertation in Business Studies: A Step by Step Assistance" by [9] John Dudovski (2016), purposive sampling is defined as a non-probability sampling technique in which researcher relies on own judgment when choosing members of population to participate in the study.

[10] Black (2010) stated that researchers often believe that they can obtain a representative sample by using a sound judgment, thus, resulting in saving time and money.

[11] While Palys, T. (2008) states that purposive sampling is virtually synonymous with qualitative research. He said that this method signifies that researcher sees sampling as a series of strategic choice about with whom, where, and how the research is done. This statement implies that researchers 
sample must be tied to their objective. A second implication says that there is no one best sampling strategy because which is best will depend on the context in which researchers are working and the nature of research objectives.

\subsection{Respondents}

This study was conducted in Emerson Electric Asia Ltd located at SM Cyber West Plaza building in Quezon City, Philippines. There are five (5) respondents from the Reporting Services Group in the site, two (2) from Channel Development Team in Florham Park, New Jersey, and one (1) from Strategic Marketing Team in Novi, Michigan. These people utilized the system to evaluate its features, validate its results, and ensure the security of the data being inputted in it.

\subsection{Sampling Technique}

In this respect. the Total Population Sampling (TPS) will be utilized in this study. TPS is a type of purposive sampling technique that involves examining the entire population that have a particular set of characteristics, which is typically very small.

\subsection{Data Gathering Techniques}

In systematic software development, data collection is very vital and critical to the analysis. It is the process of gathering and measuring information on targeted variables in an established systematic fashion, which then enables one to answer relevant questions and evaluate outcomes.

The accuracy of data collection is essential in maintaining the integrity of research, regardless of the field of study or data preference - quantitative or qualitative. Moreover, the selection of appropriate data gathering instruments, as well as procedures, reduce the likelihood of errors and saves cost and time.

To ensure the data gathered are both defined and accurate, the researcher should conduct a formal data collection process. In this manner, the subsequent decisions based on arguments embodied in the findings are also guaranteed. This proper way of data gathering provides both a baseline from which to measure and in certain cases a target on what to improve.

Discussed below are the data gathering methods and instruments used by the proponent in collecting the requirements of this capstone project.

- Brainstorming. This method is a group of creative means by which efforts are made to find a conclusion for a specific problem. Brainstorming is done by gathering a list of ideas spontaneously contributed by its members.

- Questionnaires. This research instrument consists of a pre-defined series of project-related questions for the purpose of gathering information from a group of respondents. Questionnaire is one of the most practical method of data collection. In the annual report published by The Standish Group in 2010, it says that the success rate of software projects in "Chaos Report" from 1994 to 2009 is based on the data collected either through surveys or questionnaires. Moreover, through this method, the results can usually be quickly and easily quantified by either a researcher or through the use of a software package.

- Interviews. This is the most common technique for gathering requirements to identify the exact needs of the clients. It can be done with one person only or with a focus group. There are several reasons why conducting interviews is a viable option as a research instrument. Some of these reasons according to Gray (2004) are the following:

- A need to attain highly personalized data

- Opportunities for probing to get underlying factors

- Limited respondents and a good return rate is important

- Respondents are not fluent in the native language of a country, or have difficulties with written language

- Observation. This technique is an effective way of deciphering how a user does their job by conducting an assessment of their work environment. It increases the familiarity of the researcher with the culture and working style of a group of people. Observation is also useful in verifying and delivering instant requirements worthy of consideration. This practice is best applied when there is a current process that is being monitored and targeted to be enhanced or improved.

\subsection{Data Gathering Preparation and Procedure}

Together with the clients and ASCO Manila Operations Manager, the proponent and the analysts sat down in a twoday brainstorming sessions to identify the basic requirements and lay-out a plan to successfully complete this capstone project.

After which, the proponent prepared questionnaires which were validated by the ASCO Manila Operations Manager. Upon approval by the latter, the proponent distributed the questionnaires to the identified respondents.

To support and validate the data gathered from the initial means, the proponent also conducted one-on-one and group interviews with the current owners of the process. Since the existing POS data processing for each ASCO division differs in some sense, group interviews helped in aligning the process into one. The proponent also collected the common issues encountered with the current process through interviews.

Lastly, the proponent also did some observation and collected data from it. The proponent sat side-by-side with the process owner and draft in flowchart the current practice that is presently followed. Moreover, as the initial owner of the process and lead of the current owners at present, the proponent collated all the past issues the team has experienced with the existing procedure of AVD POS data processing.

\subsection{Criteria for Software Evaluation}

The proposed system was evaluated based on ISO 9126 Software Quality Characteristics - an international standard for the evaluation of software. The standard is divided into four parts which addresses, respectively, the following subjects:

\begin{tabular}{ll} 
- & Quality model \\
- & External metrics \\
- & Internal metrics \\
\hline
\end{tabular}

ISO 9126 Part one, referred to as ISO 9126-1 is an extension of previous work done by [9] McCall (1977), Boehm (1978), FURPS and others in defining a set of software quality characteristics. 


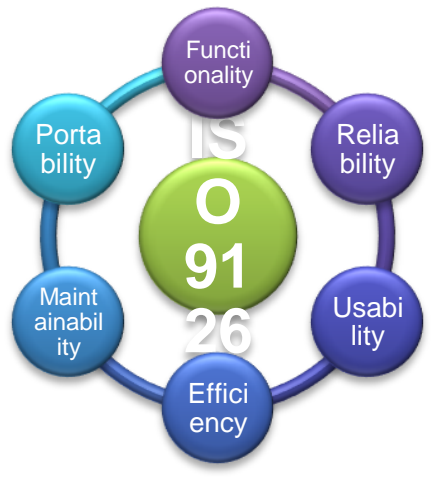

Figure 4. ISO 9126

- Functionality. This characteristic is the essential purpose of any product and service. This refers to attributes that bear on the existence of a set of functions and their specified properties. The functions are those that satisfy stated or implied needs. The subcharacteristics underlying this feature are suitability, accuracy and interoperability, and security.

- Reliability. This is a set of attributes that bear on capability of the system to maintain its service provision under defined conditions for defined periods of time. The sub-characteristics underlying this feature are maturity, fault tolerance, and recoverability.

- Usability. This is a set of attributes that bear on the effort needed for use, and on the individual assessment of such use, by a stated or implied set of users. The subcharacteristics underlying this feature are understandability, learnability, operability, attractiveness.

- Efficiency. This is a set of attributes that bear on the relationship between the level of performance of the software and the amount of resources used, under stated conditions. The sub-characteristics underlying this feature are time behavior and resource utilization.

- Portability. This is a set of attributes that bear on the ability of software to be transferred from on environment to another. The sub-characteristics underlying this feature are adaptability, installability, replaceability, and co-existence.

- Maintainability. This is a set of attributes that bear on the effort needed to make specified modifications. The sub-characteristics underlying this feature analyzability, changeability, stability, and testability.

\subsection{Statistical Data}

Weighted Mean. A weighted mean is a kind of average wherein some data points contribute more weight than the others, instead of each contributing equally to the final mean.

Shown below is the technical formula to compute for the weighted mean:

\subsection{Project Development}

$$
\bar{x}=\frac{\sum_{i=1}^{n}\left(x_{i} * w_{i}\right)}{\sum_{i=1}^{n} w_{i}}
$$

The proponent used the Evolutionary Prototype Model in developing the system as illustrated in the Figure 3.1 below. Evolutionary prototyping, also known as breadboard prototyping, is based on building actual functional prototypes with minimal functionality in the beginning. The prototype developed forms the heart of the future prototypes on top of which the entire system is built.

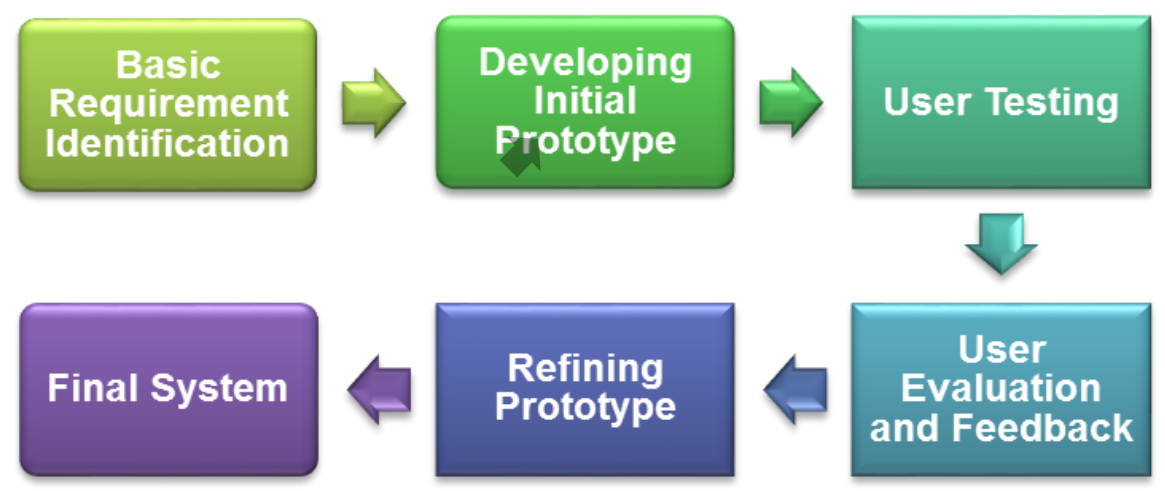

Figure 5: Prototyping Methodology

1. Basic Requirements Identification - In this phase, the proponent gathered and understood the basic requirements of the project, particularly with regards to user interface. Other than these pre-requisites, more intricate details of the internal details of the internal design and external aspects like performance and security can be ignored at this stage.

2. Developing Initial Prototype - With all the basic requirements gathered, the initial prototype is developed in this stage. This showcases the user
The initial prototype is developed in this stage, where the very basic requirements are showcased and user interfaces are provided. These features may not exactly work in the same manner internally in the actual software developed and the workarounds are used to give the same look and feel to the customer in the prototype developed.

3. User Testing - The prototype developed is then presented to the customer and the other important stakeholders in the project. The feedback is collected in 
an organized manner and used for further enhancements in the product under development.

4. User Evaluation and Feedback - The feedback and the review comments are discussed during this stage and some negotiations happen with the customer based on factors like, time and budget constraints and technical feasibility of actual implementation. The changes accepted are again incorporated in the new Prototype developed and the cycle repeats until customer expectations are met.

5. Refining Prototype - The second prototype is evaluated in the same manner as was the first prototype. The preceding steps are iterated as many times as necessary, until the users are satisfied that the prototype represents the final product desired.

6. Final System - The final system is built based on the final prototype. The final system is thoroughly evaluated and tested. Routine maintenance is carried out on a continuing basis to prevent large-scale failures and to minimize downtime.

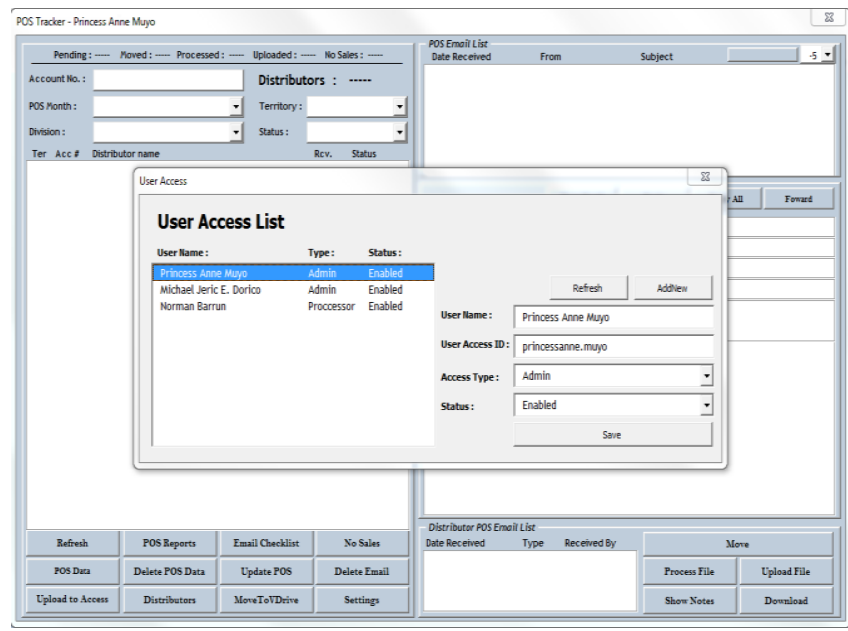

Figure 6: Level of Access

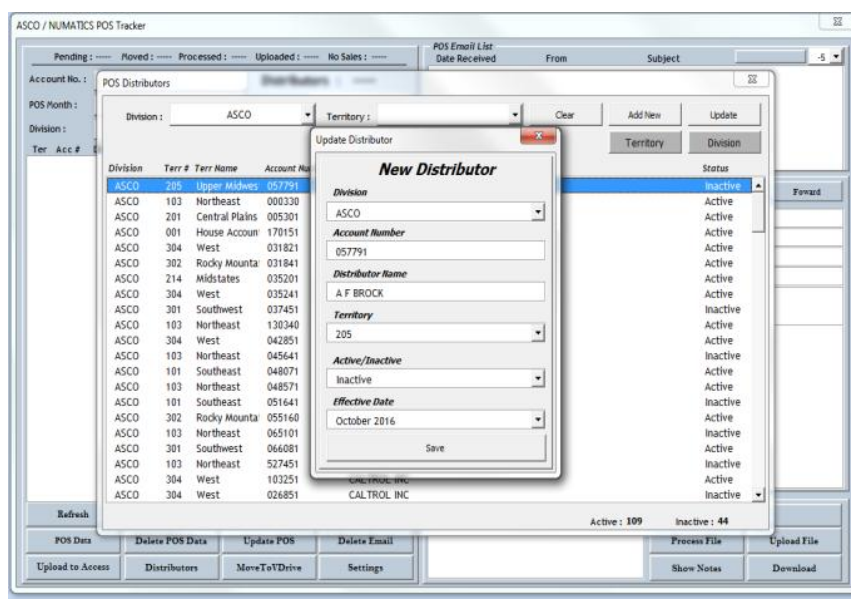

Figure 7: System Prototype

\section{RESULTS AND DISCUSSION}

\subsection{Project Description}

ASCO AVD POS Data Management system is an MS Excel VBA project made to lessen the problems encountered by ASCO US Reporting Services Group with the existing process of managing AVD POS data.

\subsection{System Requirements}

ASCO AVD POS Data Management System requires the following specifications in order for the application to run as expected.

Hardware:

1. Computer / Laptop

Software:

1. Windows

2. Microsoft Outlook 2007-2016

3. Microsoft Excel 2007-2016

4. MySQL ODBC Connector 5.1 or higher

5. SQL 2008 Management Studio

Network Access to Emerson Intranet

Presentation of Level of Access

- Administrator

Below demonstrates the access page of the processor. Processor is a user who is mainly responsible on the end-toend process of AVD POS data management.

\subsection{Presentation of AVD Detail and E-mail Management}

Figure 4.4 displays the screenshot of system's main frame showing the e-mails for the selected month and division. In this frame, the user can have a glimpse of the list of the AVDs, their submission status and receipt date of their POS.

Displays the frame when the administrator adds and updates AVD details. As soon as this is saved, the List of AVDs (Figure 4.5) will be updated.

\section{- POS Details and Log Sheet}

This is an MS Excel log sheet containing the following information for the selected month:

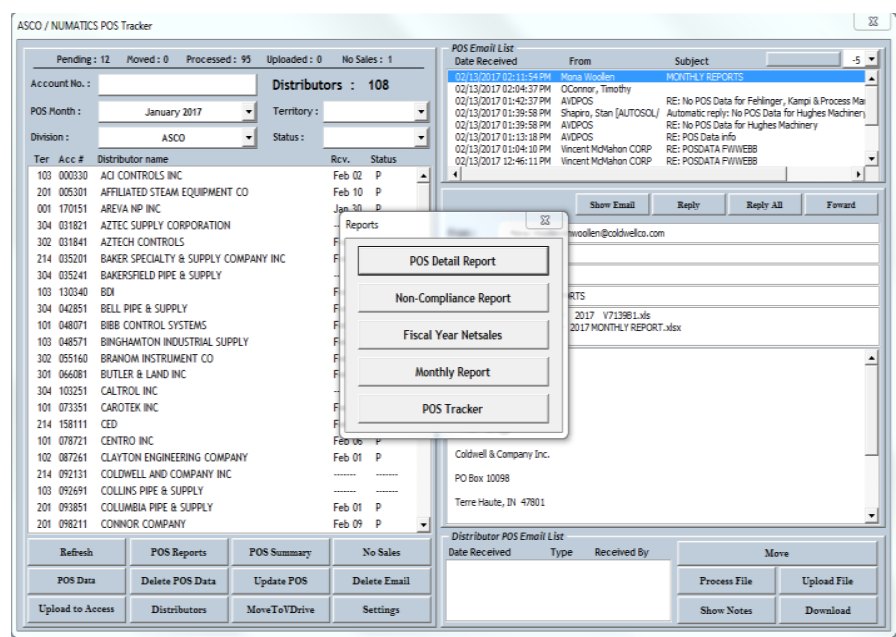

Figure 8: Generating AVD POS 


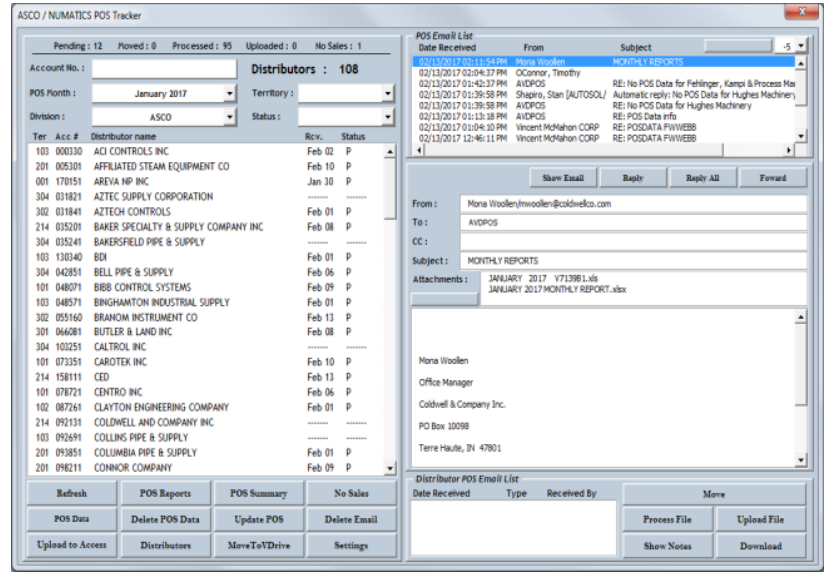

Figure 9: Distributor Process

\subsection{Presentation of Generated Reports}

It shows the window when the user clicks the "POS Reports" button. This gives the users options of which report to generate.

\begin{tabular}{|c|c|}
\hline Column Name & Definition \\
\hline Terr & Region where the distributor belongs \\
\hline Account Number & UniquelD of the distributor \\
\hline Distributor Name & Name of the distributor \\
\hline Date Received & Date received the e-mail containing the POS file \\
\hline Template & File format (CSV/Fixed Length) \\
\hline Attachment Name & File name of the attached document in the e-mail \\
\hline POS Status & Status of the POS file (Moved/Processed/Uploaded) \\
\hline Received By & Username of the person who received the file \\
\hline Tracked Date & Date when the e-mail has been tracked/archived \\
\hline Processed By & Username of the person who processed the file \\
\hline Processing Date & Date when the e-mail has been processed \\
\hline Uploaded By & Username of the person who uploaded the file \\
\hline Upload Date & Date when the e-mail has been uploaded \\
\hline Notes & Additional information/notes \\
\hline
\end{tabular}

\section{Figure 11: Distributor Details}

Assignment of POS file and/or record type of the e-mail POS or Documentation.

It displays the window when the users add in or view notes on the data submitted by the AVD.

\section{- AVD Net Sales}

This report shows the monthly sales performance of each AVD per territory in database and graphical format.

The graphical representation of each AVD Net Sales gives a clue to the analyst if they processed the data correctly in terms of sales. At the same time, give an insight on the top and least performing AVD of the region per month.

\section{- POS Tracker}

The POS Tracker Report which includes details like Received Date and Number of Days Late. This report gives the users a summarized performance report of AVDs in terms submitting their monthly POS file.

The AVDs with poor performance in terms of timeliness are communicated to the Regional Sales Directors. This report helps the users to identify such.

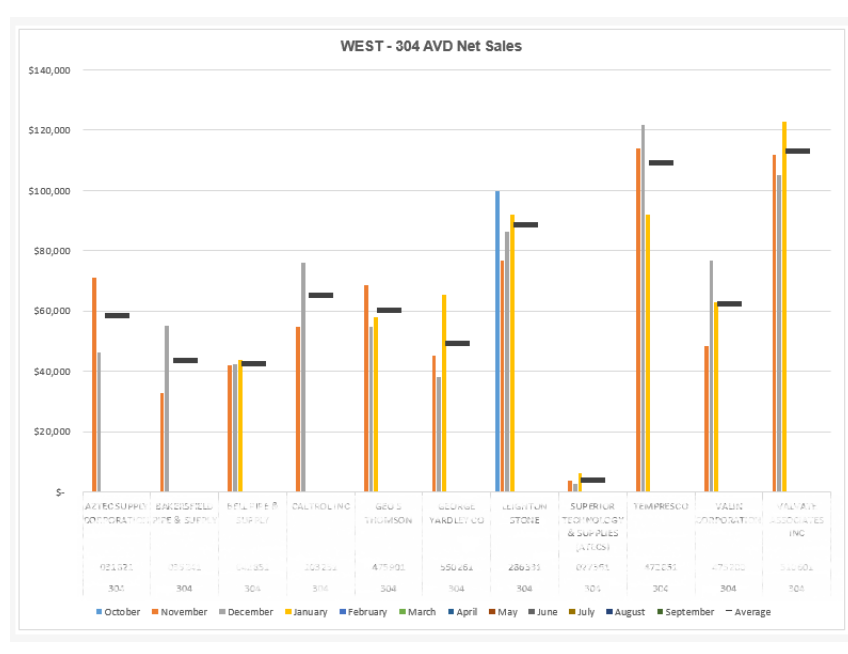

Figure 12: Screenshot of the AVD Net Sales Graph per Region

With regards to portability, the system had an impressive score yielding an average weighted mean of 4.69 interpreted as "Strongly Agree."

The first statement in this evaluation, "The system requires minimal set-up time.", scored a weighted mean of 4.70 . The next one, "The tools needed to run the system is available in the online market anytime", gained a weighted mean of 4.80. The third, "The system can be set-up with minimum or recommended system requirements." was graded 4.70. Finally, "The system occupies minimum hard disk storage space." was rated 4.80. All of which are interpreted as "Strongly Agree".

In summary, the proposed system yielded an overall mean of 4.34 which is interpreted as "Agree". Shown in Table 4.9 is the synopsis of the evaluation conducted per ISO 9126 criteria.

\begin{tabular}{|c|c|c|}
\hline Criteria & Weighted Mean & Description \\
\hline Functionality & 4.78 & Strongly Agree \\
\hline Reliability & 3.92 & Agree \\
\hline Usability & 3.91 & Agree \\
\hline Efficiency & 4.48 & Agree \\
\hline Maintainability & 4.18 & Agree \\
\hline Portability & 4.75 & Strongly Agree \\
\hline OVERALL & 4.34 & AGREE \\
\hline
\end{tabular}

Figure 13: Summary of Results

\section{RECOMMENDATION}

With all the results presented in the previous chapter, the following conclusions were derived based on the concerns stated in the objectives of the study and results of the evaluation conducted: 
1. The ASCO AVD POS Data Management System was successfully developed such that:

a. The system tracks the date when the AVD send their monthly POS report to ASCO.

b. The system properly archives AVDs' emails to the designated folder.

c. The system provides a feature where users can generate and/or view reports that are related to AVD sales performance and POS submission.

d. The system gives the users a quick view on the historical sales of the AVD.

e. The system can create and store a dynamic template for AVDs submitting POS in CSV format.

2. The performance of software application passed the evaluation of the respondents who are future the users of system as well. The system rating was interpreted as "Agree" in terms of functionality, reliability, usability, efficiency, maintainability and portability that yielded an overall mean of 4.34 . Thus, it can be concluded that the software can now be implemented in the production.

\subsection{Recommendations}

For the advancement of the ASCO AVD POS Data Management System, the proponent gives and collates the accompanying changes and proposals based on result of the study and feedback from evaluators. The following are recommended to further improve the developed project:

1. Create a more detailed user manual that uses terms that is understandable in general.

2. Create a button in the system which will direct the users to the system user manual.

3. Put a description in each button when the user hovers the mouse.

4. Improve on system recoverability after downtime.

5. Add confirmation box on critical actions such as deleting e-mails and POS file, uploading data, and updating AVD details.

6. Automate the data cleansing and normalization.

7. An option to maximize and minimize the system main frame.

\section{REFERENCES}

[1] "Company History: The ASCO Story". (n.d., para. 1). Retrieved from http://www.asco.com/enus/pages/history.aspx

[2] "ASCO Introduces Engineered Solutions Program". (2016., para. 7). Retrieved from http://www.emerson.com/en-us/news/automation/ascointroduces-engineered-solutions-program

[3] The DAMA Guide to the Data Management Body of Knowledge (DAMA-DMBOK) Print Edition (2010). Introduction \& Project Status.

[4] DAMA Intenational (2011) DAMA-DMBOKGuide Context Diagram: Participants. Retrieved from http://www.damaindiana.org/Presentations/DAMA\%20I ndiana\%20Data\%20Architecture\%20Management.pdf

[4] Christ P. (2012) KnowThis: Marketing Basics

[5] Quinn E. (2013) Case Study: B2B Exchange Supercharges Zyme Solutions and Its Customers. Retrieved from: https://www.informatica.com/content/dam/informaticacom/global/amer/us/collateral/customer-successstory/zyme-solutions_case-study_2415.pdf

[6] DAMA Intenational (2011) DAMA-DMBOKGuide Context Diagram: Participants. Retrieved from http://www.damaindiana.org/Presentations/DAMA\%20I ndiana\%20Data\%20Architecture\%20Management.pdf

[7] Market Overview: Channel Data Management. (2013) The Gateway to Channel Sales and Marketing Visibility. Retrieved from https://www.forrester.com/report/ Market+Overview+Channel+Data+Management/-/ERES94801

[8] Greenberg C. (2015) The Importance of Channel Data Management and the Difference that Drives Revenue Growth. Retrived From http://www.sdcexec.com/article/12146536/theimportance-of-channel-data-management-and-thedifference-that-drives-revenue-growth

[9] Dudovskiy J. (2016 )The Ultimate Guide to Writing a Dissertation in Business Studies: A Step-by-Step Assistance

[10] Black (2010) Purposive sampling is a non probability sampling.

[11] Palys, T. (2008). Purposive sampling. In L.M. Given (Ed.) The Sage Encyclopedia of Qualitative Research Methods. (Vol.2). Sage: Los Angeles, pp. 697-8. 